\title{
Identical in Appearance but Not in Actuality: Headings Shared by a Subject-Access and a Form/Genre Access Authority List
}

\section{David Miller}

Authority records were compared for established headings that are identical in Library of Congress Subject Headings (LCSH, 18th edition) and MovingImage Materials: Genre Terms (MIM). First, the Use For, Broader Term, Narrower Term, and Related Term references in the LCSH authority file were compared with their counterparts in MIM, to determine the proportion of duplication existing between them. Fewer than 10\% of these reference headings are identical. Second, a qualitative comparison was made of the "semantic spaces" inhabited by identical headings in different contexts: a general-purpose subject access list as compared with a medium-specific form/genre access list. It was found that, in many cases, headings that are identical as character strings have markedly different meanings in different contexts. The conclusion offered is that, both quantitatively and qualitatively, pairs of identical headings differ sufficiently from each other that the creation of authority records for each usage represents no duplication in any meaningful sense. The striking divergence, in many instances, between semantic spaces provides food for thought on the differences between the naming of subjects and of forms/genres.

\begin{abstract}
A A the American Library Association (ALA) Annual Conference in June 1995, the Machine-Readable Bibliographic Information Committee (MARBI) considered Proposal 95-11, "Definition of X55 Fields for Genre/Form Terms in the USMARC Authority Format" (StocktonSan Joaquin County Public Library 1995). MARBI, an interdivisional joint committee of ALA, is concerned with the creation, review, and development of standards for
\end{abstract}

the presentation of bibliographic information in machine-readable form. Proposal 95-11 establishes authority heading fields (MARC fields 155, 455, 555, 755) corresponding to field 655 (Index TermGenre/Form) of the USMARC Bibliographic Format (Library of Congress, Network Development and MARC Standards Office 1991, 126). The history of this issue, first raised in 1993 and pursued through two discussion papers and two

David Miller (dmiller@curry.edu) is Head of Technical Services, Levin Library, Curry College Milton, Massachusetts. Manuscript received February 10, 1997; accepted for publication April
25, 1997. 
proposals, is covered in the text of Proposal 95-11. The driving force was the desire on the part of some librarians to create authority records for form/genre headings, as subject authority records are now. This would be the case even in instances where headings of each type, drawn from different thesauri, appeared to be identical, in order to allow for cross-references and notes that apply only to one thesaurus.

The new fields proposed were accepted as part of the USMARC Authority Format, but concern was expressed, in the proposal itself and in committee discussion, about the apparent duplication mandated by creating separate authority records for identical headings. In the proposal, the question was raised whether it would be preferable to create two authority records for the same term-one a topical heading (tagged as 150), the other a genre/form term (tagged as 155). It was also asked whether the duplication of identical terms would prove confusing to the user (Stockton-San Joaquin County Public Library 1995). The potential adverse consequences of duplication in indexing were mentioned in committee discussion, but these were not regarded as sufficient to prevent acceptance of the proposal (ALCTS/LITA/RASD 1995).

These speculations about potential indexing and display problems raise the question of whether separate authority records for the same heading, used for subject and form/genre access respectively are in fact duplicates. Besides the established headings, which are necessarily identical as character strings, what sort of parallelisms between such pairs of authority records would actually exist? This question, which can be addressed both quantitatively and qualitatively, was investigated by comparing identical headings drawn from the Library of Congress Subject Headings (LCSH) and MovingImage Materials: Genre Terms (MIM).

LCSH is a well-known list of subject headings applied by catalogers in the United States and other countries, developed and managed by the Library of Congress (LC). MIM was developed by the National Moving Image Database Standards Committee of the National Center for Film and Video Preservation at the American Film Institute. The stated purpose of the list was "to standardize terms used to designate genres and forms of moving image materials" (Yee 1988, 11). It is a general list, best suited to collections that contain many different types of moving-image materials, and has been designed to apply across media. Headings from $M I M$ are entered in USMARC bibliographic field 655 .

\section{BACKGROUND OF THE STUDY}

The present study is the third in a series of writings originating from the close comparison of MIM and LCSH. Miller (1992) examined the levels of compatibility between the lists, using the LC Subject Authority File to represent LCSH. The study was conducted in order to determine the potential for conflict or ambiguity if the two lists were used and indexed together in a general academic library catalog. It was determined that, while most of the approximately 190 MIM headings presented no conflicts with $\mathrm{LCSH}$, either conceptually or as character strings, there were five categories of headings that presented potential problems of overlap and synonymy. These were (I) headings that might be synonymous with those in $L C S H$, (2) headings that are similar in wording to related headings in $\mathrm{LCSH}$, (3) headings that are identical in form between the two lists, (4) headings that serve as "see" references in $\mathrm{LCSH}$, and (5) homographs: headings identical in form but referring to different areas of knowledge.

Miller (1995) began with a set of LC subject headings drawn from the first three categories described above, that is, headings that might be considered synonymous, similar, or identical with those in MIM. The OCLC Online Union Cata$\log$ was searched for records that contained those subject headings in an attempt to determine whether they were used for subject or form/genre access and in what proportions. The major finding of that study was that this set of "subject" headings was used for form/genre access between $6 \%$ and $99 \%$ of the time, with a mean of just over $50 \%$. In only a few instances 
did authority record information mandate form/genre use. Nevertheless, it was clear that form/genre access to the cataloged materials was regarded as essential and was provided by catalogers. Subject headings from $L C S H$ were therefore being pressed into service as a kind of movingimage form/genre thesaurus-however partially and inconsistently.

It is the third category of headingsthe 27 headings that are identical in form between the two lists-that we consider in the present study. The entire population of these headings, which are applied to works used for the study of moving-image materials, therefore serves as a basis for the comparisons that follow (the list of 27 headings is included as appendix A). These headings, which are identical in form and apparent duplicates, were compared to determine the extent to which they are synonymous in meaning.

Together, these three studies can be regarded as bases for considering several questions associated with using multiple thesauri for both subject and form/genre access. What kinds of compatibility exist among thesauri, and how might the incompatibilities be managed? Can a mainstream list, intended primarily for subject access, be adapted for effective form/genre use in lieu of specialized thesauri? What does it mean to say that headings are identical when drawn from lists developed for different purposes? The usefulness of the present study, then, lies both in what it might say about $L C S H$ or MIM per se and in its potential for replication with other subject heading populations and lists.

\section{ASSUMPTIONS AND LITERATURE REVIEW}

Three assumptions underlie these studies. The first is that an item's subject is conceptually distinct from the form or genre it exemplifies. That is, an item's “aboutness" is separate from its nature as a physical, intellectual, or aesthetic entity. While some genres, such as Western novels, presuppose subject matter in a general way, this should not lead us to assume that subject and form/genre are similar concepts. The second assumption is that explicit, separate provision of access to subjects and forms/genres is desirable as a service to the end user. The third assumption is that end users intuitively understand the difference between "is" and "is about," even if they do not articulate that understanding in searching behavior or reference interviews. These assumptions are subject to debate, but are here taken as givens.

Miller (1995) provides a brief literature review of writings concerned with subject and form/genre access issues. For recent developments in this area, a good source can be found in Taylor (1997). This site includes documents related to the work of the ALA/ALCTS/CCS Subject Analysis Committee Subcommittees on Form, from 1991 to the present. At LC, a Form/Genre Working Group, headed by the assistant chief of the Cataloging Policy and Support Office, has been working since 1995 to develop this access throughout LC's collections (Yee 1997). This complex, long-term effort has great potential to bring multiple benefits to the broader library community in terms of rationalized vocabularies, systems development, and redeveloped cataloging practices. Another source of current developments is the electronic discussion list GSAFD (Library Subject Access to Fiction). Discussions in this forum frequently include debates about literary genre headings, their scope and appropriateness for different collections.

\section{OBJECTIVES OF THE STUdY}

In the study described here, two types of comparison were made:

1. Quantitative comparison. Authority headings were compared for those headings whose authorized forms are identical in $L C S H$ and MIM to determine the nature and percentages of references shared by each pair of records. It was assumed that the only elements of subject authority records that could be compared quantitatively (besides the established headings), were the reference headings, e.g. Use For (UF). Other elements, such as note fields or classification 
number fields, are rarely if ever identical in authority records based on different lists, and no attempt was made to score similarity of these elements.

2. Qualitative comparison. Authority headings were compared to determine the extent to which identical headings in the two lists designate identical or analogous concepts. This aspect of the study clearly involved subjective evaluation, which, although not susceptible to counting and scoring, nevertheless can provide a basis for discussion about the use of established headings as means of naming particular concepts in specific contexts.

\section{Method}

For the quantitative comparison, authority records for identical $L C S H$ and MIM headings were compared for the presence of identical references. Two categories were derived: identical references in identical positions and identical references in different positions.

"Identical references" are reference headings that have identical character strings as the established headings. "Identical positions" refers to the functions that the references serve in authority records: Use For, Narrower Term (NT), Broader Term (BT), Related Term (RT), or See Also From (XX). (See Also From is in MIM only and is rarely used.) As an example of the first category, both lists include Beauty pageants as a UF reference for the established heading Beauty contests. As an example of the second category, LCSH includes Erotic films as an NT for Erotica; MIM, by contrast, lists Erotic films as a UF reference for Erotica.

Two further categories of references were also derived: similar references in identical positions and similar references in different positions.

Similar references are reference terms that are similar, though not identical, character strings. Synonymy, or conceptual overlap considered generally, is not indicated. As an example of the third category, the established heading Talk shows is given two RTs in LCSH: Interviewing in radio and Interviewing in television. These are similar to Interviews, an RT given for this heading in MIM. The fourth category can be demonstrated with the established heading Concerts, a NT used in $L C S H$, which is similar to Concert films, a UF included in MIM.

It should be clear that the four types of matched references represent decreasingly rigorous categories of duplication. In fact, the first category is the only one that can be said to represent genuine duplication of elements in authority records for identical headings. The other three categories were derived, however, in order to determine the proportion of overlap between pairs of authority records, even under less precise matching conditions. This can be stated as a question: As the criteria for duplication are loosened, how is overlap affected?

For each type of reference (UF, NT, RT, BT, $X X$ ) examined, the total number of references of that type was counted for each list. For example, there were a total of 20 BTs in the MIM records examined, as compared with 51 in the related $L C S H$ records (see table 1). The number of matches obtained in each of the above categories was divided by each total to determine the percentage of overlap existing in each case.

For the qualitative comparison, conceptual overlap between pairs of identical terms was evaluated by comparing the semantic content of pairs of authority records. This comparison included reference terms as well as scope notes, classification numbers, and examples. Taken together, these elements provided the context for analyzing the meaning of the established heading.

\section{RESULTS AND DISCUSSION}

The results of the quantitative comparison of reference headings are presented in tables 1 through 7 (all percentages are rounded to two decimal places). In table 1 , we find that $3.78 \%$ of the MIM reference headings fall into Category 1 with respect to their counterparts in $L C S H$. The complement for $L C S H$-to-MIM comparison is $1.34 \%$. In tables 3,4 , and 6 , the equivalent percentages for Categories 24 are presented.

In tables 2 and 5 we find information 
TABLE 1

Category 1: Identical References in IdentiCal Positions

\begin{tabular}{lcccc}
\hline & \multicolumn{2}{c}{ MIM } & \multicolumn{2}{c}{ LCSH } \\
& Overlap/Total & $\%$ & Overlap/Total & $\%$ \\
\hline UF & $5 / 67$ & 7.46 & $5 / 60$ & 8.33 \\
NT & $0 / 46$ & 0.00 & $0 / 385$ & 0.00 \\
RT & $2 / 50$ & 4.00 & $2 / 26$ & 7.69 \\
BT & $0 / 20$ & 0.00 & $0 / 51$ & 0.00 \\
[XX] & $0 / 2$ & 0.00 & $0 / 0$ & 0.00 \\
Totals & $7 / 185$ & 3.78 & $7 / 522$ & 1.34 \\
\hline
\end{tabular}

Note: XX (see also from) reference terms are listed separately, rather than combined with Related Terms, in order to respect the authority record structure used in MIM.

about the nature and number of equivalences noted, when either identical or similar references were found in different positions. For example, table 2 shows that, in the case of identical references, $6 \mathrm{UF}$ references in $M I M$ corresponded to NT references in $L C S H$. One additional MIM $U F$ reference corresponded to a $L C S H$ $\mathrm{BT}$ reference.

In table 7 the percentages of overlap are totaled for the first and second categories, the third and fourth categories, and all categories considered together. When identical references alone are considered, whether in identical or different positions, less than $10 \%$ of the $M I M$ reference headings are found in the corresponding $L C S H$ authority records. The total for LCSH-to-MIM comparison is much smaller, at $3.26 \%$. When similar references are considered, the respective figures are $13.52 \%$ and $4.79 \%$. The totals for all categories of overlap stand at $22.71 \%$ of $M I M$ references identical or similar to $L C S H$ references, but only $8.05 \%$ of $L C S H$ references corresponding to those in $M I M$.

The meanings of these figures are not self-evident and will depend on the uses to which they are put. It would seem that, from a database management perspective,

\section{TABLE 2}

Category 2: Identical RefEREnces IN DIFFERENT POSITIONS

(EQUIVALENCES)

\begin{tabular}{llll}
\hline MIM & $=$ & LCSH & $\#$ \\
\hline UF & $=$ & NT & 6 \\
RT & $=$ & UF & 1 \\
NT & $=$ & RT & 1 \\
BT & $=$ & RT & 1 \\
UF & $=$ & BT & 1 \\
\hline
\end{tabular}

TABLE 3

Category 2: Identical References in Different Positions (Percentages)

\begin{tabular}{lcccc}
\hline & \multicolumn{2}{c}{ MIM } & \multicolumn{2}{c}{ LCSH } \\
& Overlap/Total & $\%$ & Overlap/Total & $\%$ \\
\hline UF & $7 / 67$ & 10.44 & $1 / 60$ & 1.66 \\
NT & $1 / 46$ & 2.17 & $6 / 385$ & 1.56 \\
RT & $1 / 50$ & 2.00 & $2 / 26$ & 7.69 \\
BT & $1 / 20$ & 5.00 & $1 / 51$ & 1.96 \\
{$[X X]$} & $0 / 2$ & 0.00 & $0 / 0$ & 0.00 \\
Totals & $10 / 185$ & 5.41 & $10 / 522$ & 1.92 \\
\hline
\end{tabular}


TABLE 4

Category 3: Similar References in Identical Positions

\begin{tabular}{lcccc}
\hline & \multicolumn{2}{c}{ MIM } & \multicolumn{2}{c}{ LCSH } \\
& Overlap/Total & $\%$ & Overlap/Total & $\%$ \\
\hline UF & $1 / 67$ & 1.49 & $1 / 60$ & 1.66 \\
NT & $8 / 46$ & 17.39 & $8 / 385$ & 2.08 \\
RT & $2 / 50$ & 4.00 & $2 / 26$ & 7.69 \\
BT & $2 / 20$ & 10.00 & $2 / 51$ & 3.92 \\
XX & $0 / 2$ & 0.00 & $0 / 0$ & 0.00 \\
Totals & $13 / 185$ & 7.03 & $13 / 522$ & 2.49 \\
\hline
\end{tabular}

\section{TABLE 5}

CATEgory 4: Similar RefERENCES IN DIFFERENT POSITIONS (EQUIVALENCES)

\begin{tabular}{llll}
\hline MIM & $=$ & LCSH & $\#$ \\
\hline UF & $=$ & NT & 2 \\
UF & $=$ & RT & 3 \\
UF & $=$ & BT & 3 \\
RT & $=$ & NT & 3 \\
BT & $=$ & UF & 1 \\
\hline
\end{tabular}

only the first two categories have any value, at least for their impact on clerical work. Let us assume a situation in which catalogers create authority records for MIM headings, for a database that already contains records for the identical LCSH headings. The act of keying a reference heading that is also identical might be regarded as an unjustifiable waste of resources. In this case, the database man- ager will want to remember that this situation obtains for less than $4 \%$ of all $L C S H$ reference headings. This is not only a trivial percentage of duplication, but is easily addressed with basic word-processing functions (e.g., copy and paste).

By contrast, the totals of all categories of overlap might be of interest from a broader perspective. If one regards similarity of headings as character strings as indicating similarity in meaning-a plausible but not inevitable assumption-then the less precise matches of categories 3 and 4 might serve as evidence that authority records for identical headings provide redundant access to the same concept. If this is true, then maintaining separate authority records that only differ in function (i.e., subject vs. form/genre) might be regarded as a theoretical nicety at best. Worse, it would give rise to the concern voiced in the June 1995 MARBI discussion, where patrons might be required to perform double lookups for

TABLE 6

Categony 4: Similah References in Different Positions (Percentages)

\begin{tabular}{lcccc}
\hline & \multicolumn{2}{c}{ MIM } & \multicolumn{2}{c}{ LCSH } \\
& Overlap/Total & $\%$ & Overlap/Total & $\%$ \\
\hline UF & $8 / 67$ & 11.94 & $1 / 60$ & 1.66 \\
NT & $0 / 46$ & 0.00 & $5 / 385$ & 1.30 \\
RT & $3 / 50$ & 6.00 & $3 / 26$ & 11.54 \\
BT & $1 / 20$ & 5.00 & $3 / 51$ & 5.88 \\
[XX] & $0 / 2$ & 0.00 & $0 / 0$ & 0.00 \\
Totals & $12 / 185$ & 6.49 & $12 / 522$ & 2.30 \\
\hline
\end{tabular}


TABLE 7

SUMMARY TOTALS

\begin{tabular}{ccccc}
\hline \hline & \multicolumn{2}{c}{ MIM: Overlap with LCSH } & \multicolumn{2}{c}{ LCSH: Overlap with MIM } \\
& Overlap/Total & $\%$ & Overlap/Total & $\%$ \\
\hline Category 1 & $7 / 185$ & 3.78 & $7 / 522$ & 1.34 \\
Category 2 & $10 / 185$ & 5.41 & $10 / 522$ & 1.92 \\
Subtotal & $17 / 185$ & 9.19 & $17 / 522$ & 3.26 \\
Category 3 & $13 / 185$ & 7.03 & $13 / 522$ & 2.49 \\
Category 4 & $12 / 185$ & 6.49 & $12 / 522$ & 2.30 \\
Subtotal & $25 / 185$ & 13,52 & $25 / 522$ & 4.79 \\
Total & $42 / 185$ & 22.71 & $42 / 522$ & 8.05 \\
\hline
\end{tabular}

the same concept. This conclusion, though, is countered by the fact that, in this case at least, a maximum of just over $8 \%$ of $L C S H$ reference terms are even similar to their MIM counterparts. That is, most of the terms present in $\mathrm{LCSH}$ authority records have either no MIM equivalents or are, at best, more or less synonymous with them. Regardless, discussions of synonymy take us out of the realm of quantitative comparison and into the second part of this study.

In any event, a string-matching argument for similarity of authority records cannot be supported in this instance. This is even more true when record elements not compared here (such as notes) are taken into consideration. On the quantitative plane, authority records for identical $M I M$ and $L C S H$ headings must be considered to have no significant similarities.

\section{QUALITATIVE COMPARISON}

The task of determining the possibility of overlap in meaning between identical headings found in different lists is not one amenable to counting or scoring. What is involved is a consideration of the microcosmic worlds of subject authority records as semantic spaces. In such a semantic space, each element (including fixed-field elements in machine-readable records) can potentially contribute to understanding the meaning of the established heading, within the context of a particular list. We are not concerned, for the moment, with whether or not such a space expresses the meaning intended by the list's creators. Rather, we focus on analyzing the meaning connoted by authority record elements, as actually present in any given record. The subjectivity involved in this task seems analogous with that involved in literary criticism. While different critics might arrive at markedly different interpretations of a text, the text in its concrete form serves as an objective point of reference for those different readings (let us set aside, for the time being, the mutability of electronic texts). This preserves the second part of this study from what might otherwise be considered mere impressionism.

The examination of authority records as semantic spaces has received very little attention in the literature. This is probably because most of the literature on authorities has focused on macrocosmic issues such as syndetic structure and the control of synonyms, issues that are critical to the construction and application of any thesaurus or term list. In addition, most authors writing about authorities have considered only a single list, in which case the question of comparative meanings does not arise.

In his study of the webs of meaning created by See Also-linked headings, Sinkankas (1972, 8-9) writes:

Words are ambiguous, meaning is slippery, connections are based upon a system of facets of meaning that are felt but not stated. LC does not help in this manner [matter?], having failed to explain a term or its subject coverage about ninety per- 
cent of the time. Scope notes and examples are given only when the situation crys [sic] out for them, and many times not even then. It may be possible to get around this problem by going to the LC classification tables, which are many times more comprehensive in their delineation of subject coverage. Often the classification notation (alphanumeric) is included after the subject heading in the LC list, which will speed matters, Where they are not, educated guessing will have to suffice.

Schmierer (1980) describes the "authority data for particular different access points" as typically including the established heading, variant forms, information both about the established heading considered and related established headings, and information sources consulted. She writes (p. 601) that the data "are maintained together so that when an established authorized form is used as an access point, its use may be understood in a context." A working group of the International Federation of Library Associations and Institutions (IFLA) developed the Guidelines for Subject Authority and Reference Entries, which provides definitions of the terms "cataloguer's note," "information note," and "scope note," as well as examples of application (International Federation of Library Associations and Institutions 1993).

Bearman and Szary (1987) discuss authorities as reference files in a multidisciplinary setting. They contend (p. 73) that "as soon as we accept the concept of authority files as information sources in themselves, apart from the 'bibliographic' or other files whose fields they 'authorize,' it becomes necessary to reexamine the types of information they contain, how they are structured, and the integrity of the data they hold." Indeed, Bearman and Szary (p. 75) propose a situation more complex than is considered here, with "multiple, independent authorities at the field level [where] conflicting authorities may control disputed values of the same field within a record!" This transformation of the authority record clearly complicates the idea of semantic space; the context in which an established head- ing is embedded would be broadened to reveal its connotations across disciplines. Olszewski (1994) more modestly advocates the use of the OCLC Authority File as a valuable information source in its current state. While he focuses on biographical and historical information contained in name authority records, his discussion emphasizes the value of record elements beyond the established heading.

It should be noted that there are also a number of authors who have examined the macrocosmic semantic spaces generated by the relationships between established headings in a list. Sinkankas (1972) performed an extended investigation of see-also relationships. Richmond (1973) discovered an extensive library science thesaurus contained within the Engineers Joint Council's Thesaurus of Engineering Terms. Johnson and Cochrane (1995) described a technology for creating a spatial array of terms from the INSPEC Thesaurus. Here, the semantic space was made visual, as a hierarchical array of narrower, broader, and "top" terms contrasts with a cloudlike display of related terms, described as a "space of loose associations" (abstract). This spatial display is a feature of the search tool itself, in contrast to Sinkankas" large graphical representation and Richmond's conceptual extrapolation of their respectively studied macrocosms.

Two sets of semantic spaces, as demonstrated in authority records for the headings Gossip and Drama, will be analyzed here. As used in LCSH, Gossip is situated in the realm of ethical problems (see figure 1). It is related to Slander, has the narrower term Talebearing, and is assigned the Library of Congress classification number BJ1535, "Special vices." Gossip is unambiguously regarded in this context as a vice, a near neighbor to, if not identical with, outright lying. In $M I M$, by striking contrast, Gossip is regarded as information about a person, particularly a celebrity, which is essentially true (see figure 2). Its broader term is Documentaries and factual films and video, and it is assigned the related terms 


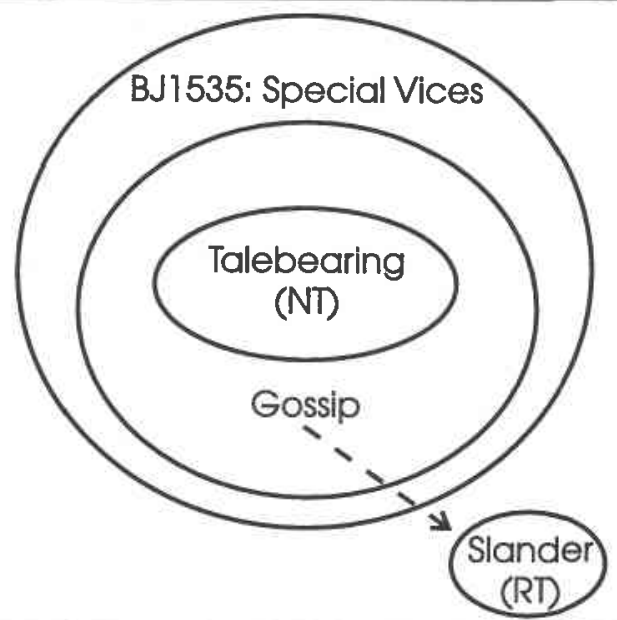

Figure 1. Gossip: $L C S H$

Context: Ethics

Biographies, News, and Magazines. The scope note (Yee 1988, 53) reads "Use for nonfiction films and programs which relay rumors, anecdotes, likes and dislikes, personal history, etc. of celebrities." The inclusion of "rumors" modifies the truth value of Gossip to an extent, but not enough to neutralize its documentary, nonfictional, biographical nature. We are also reminded that the heading is used for instances of broadcast gossip, rather than studies of communication ethics, in its relation to Magazines (e.g., 60 Minutes).

The heading Drama presents a subtler distinction in usage. The use of Drama in $L C S H$ encapsulates the ambi-

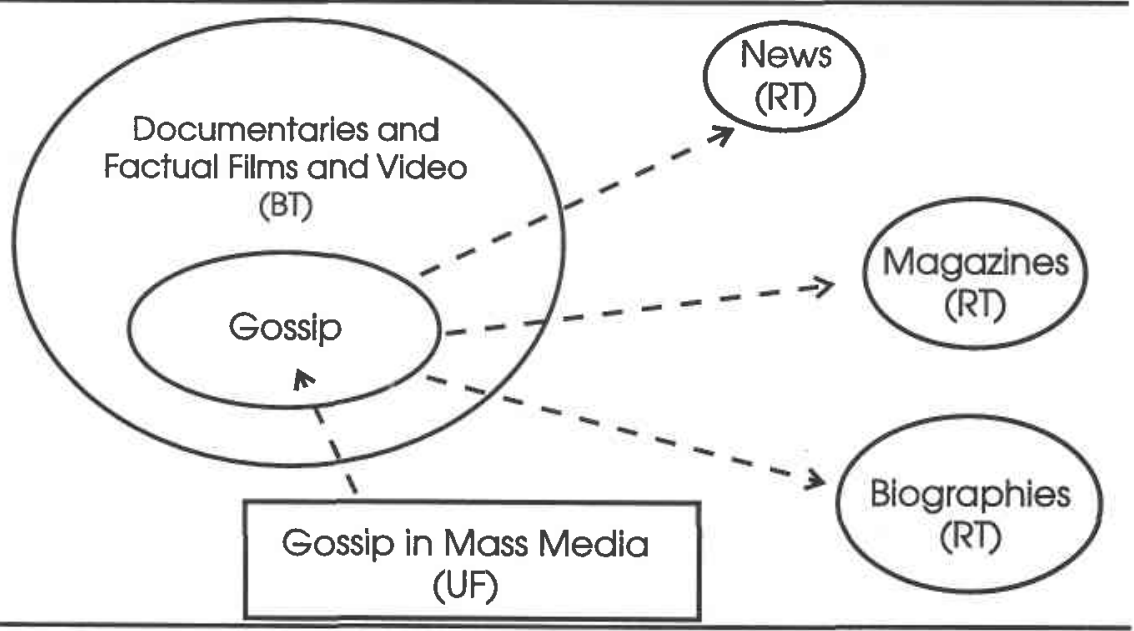

Figure 2. Gossip: $M I M$

Context: Infotainment

"Nonfiction films and programs" 


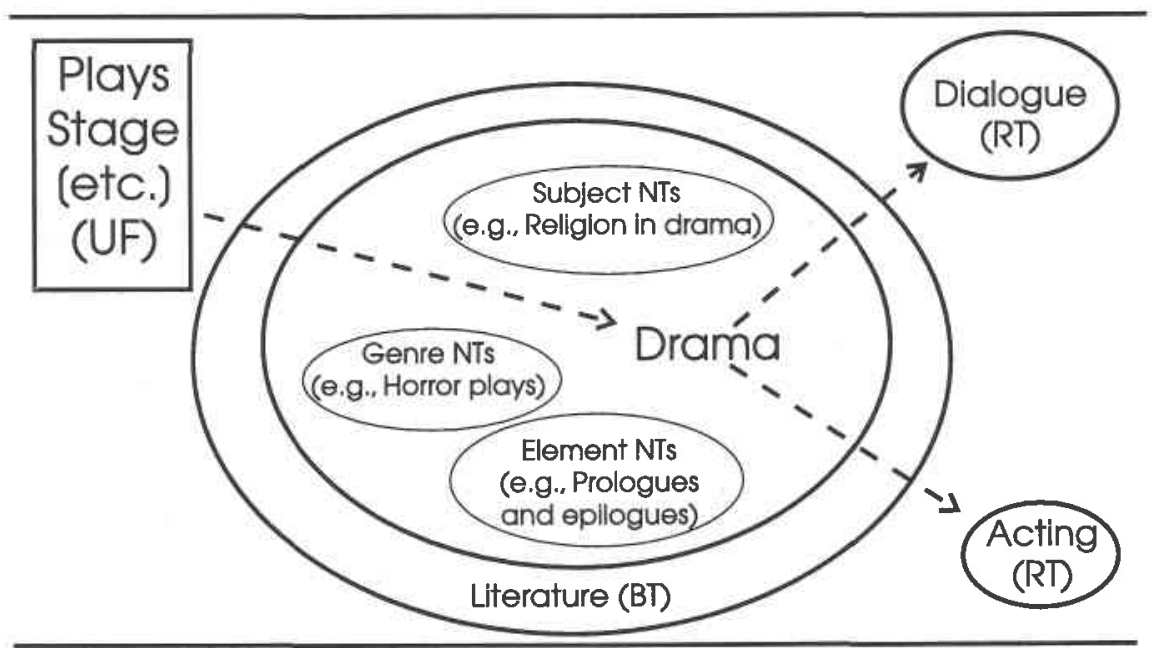

Figure 3. Drama: $L C S H$

Literary form related to stage production

guity that pervades the study of dramatic literature, a study poised between literary analysis and stage practice (see figure 3 ). The heading is grounded in Literature, the encompassing BT, reinforced by three of its four UF terms, Plays, DramaPhilosophy, and Drama, Modern. At the same time, it is related to the headings Acting and Dialogue, the former not fundamentally a literary matter, and its fourth UF term is Stage, upon which Acting happens. Its fifty-three NTs fall primarily into three categories: dramatic genres such as Horror plays, subjects such as Religion in drama, and elements of playwriting such as Prologues and epilogues. None of the NTs relate directly to the practice of theater produc-

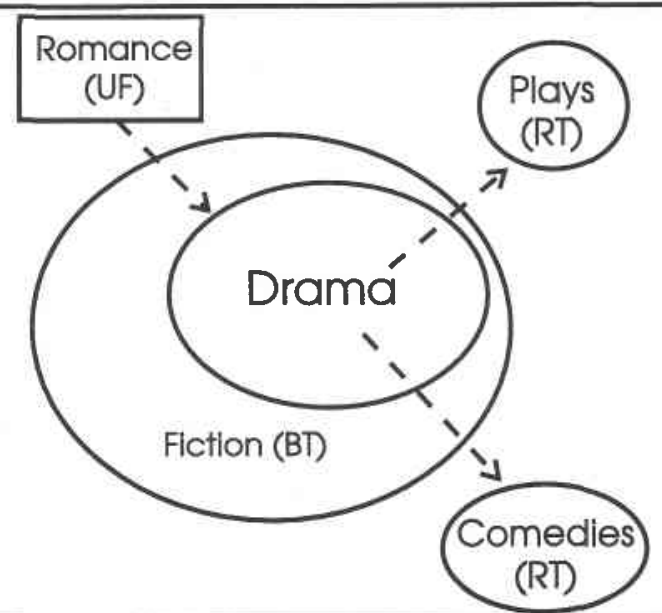

Figure 4. Drama: $M I M$

Fiction genre separate from stage production 
tion, with the possible exception of Promptbooks. The heading Drama, then, is intended to designate a literary form, closely connected with stage production.

In $M I M$, Drama designates a genre of televised or filmed fiction, without direct connection to the stage (see figure 4). Its BT is Fiction, which has to do with "imaginary characters and events" rather than literature (Yee 1988). Its scope note (44), "use for fictional works of serious intent, emphasizing conventions of character and narrative development through conflict and cathartic resolution," marks Drama as a type of fiction distinct from Comedies, one of its RTs. The other RT, Plays, is reserved for documentation of live play performance. Drama in MIM thus already pertains to the work as produced for a viewing audience, rather than a text that serves as an object for critical study. Additionally, while a viewing audience is implied at a secondary level in $\mathrm{LCSH}$, the medium and nature of production, live theater, is different.

In each of the 27 cases studied, comparative examination of the semantic spaces occupied by the "identical" headings in each list reveals more or less marked differences of meaning. Not every comparison shows as dramatic a distinction as that between the two meanings of Gossip or as subtle as that of Drama. While limitations of space prevent a discussion of every pair of headings, two additional cases can be mentioned. The authority records for the heading Talk shows point to very similar meanings; that is, the idea of what a "talk show" is seems to be similar whether considered as subject or as genre. By contrast, the records for Music create quite distinct spaces. In LCSH, Music connotes Western classical music primarily, but the entire sphere of music and its impact on human culture by extension. In $M I M$, the heading is used exclusively for recordings of live performances. But even where comparative meanings are superficially similar, the distinction between subject and form/genre access underlying the two lists means that the entities indexed by "identical" terms will, in most cases, differ significantly from each other. If an established heading is given meaning by the elements of its authority record, that meaning is also grounded in a list's intended application.

\section{SUMMARY}

A quantitative comparison was made to determine the percentage of reference headings that were shared between authority records for 27 established headings identical in $L C S H$ and MIM. When the comparison was limited to reference headings identical in both form and function, it was found that fewer than $4 \%$ of $M I M$ references were shared with $L C S H$. Conversely, fewer than $2 \%$ of $L C S H$ references were shared with MIM. The criteria for comparison were incrementally loosened, finally to include reference headings only similar as character strings, and which may serve different functions in their authority records. Under these liberal conditions, approaching synonymy rather than identity, it was found that approximately $23 \%$ of $M I M$ headings were shared with $L C S H$. However, the converse $L C S H$-to-MIM figure was just over $8 \%$.

A qualitative study was also made of the semantic spaces created by authority records for identical headings. It was found that identical headings often have different meanings in the context of their respective thesauri. In short, the creation and maintenance of separate authority records for "identical" headings cannot automatically be assumed to be redundant effort. Additionally, the sets of resources correctly indexed by headings identical in form are likely to differ.

\section{Management Considerations}

Library managers responsible for authority control will naturally be concerned about how best to minimize conflicts between headings from multiple thesauri. The specificity of discipline-based vocabularies, while of potential benefit to users, carries with it the need to clarify the scope of similar or identical headings, among other challenges. Authors of the literature on the subject are primarily concerned with management of multiple- 
subject thesauri, a different situation from that giving rise to this study. Approaches to the multiple-subject thesaurus problem can, nevertheless, provide insights on management of form/genre lists in combination with $L C S H$ or other subject lists.

Mandel (1987, v) describes "four basic approaches to providing access to databases indexed by different vocabularies": creating segregated files, mixing vocabularies, integrating vocabularies, and providing enhanced front-end navigation. These comments will focus on the first two approaches.

The major disadvantage of the segregated-file approach, where subject access is concerned, is that users are required to perform more than one search for the same or similar concepts. However, since we are here concerned with distinguishing applications of identical headings rather than integrating them, the segregated file approach may be the simplest. Provision of a form/genre index, with headings drawn from USMARC 655 fields, could provide clearly distinguishable access to items of particular types, rather than works about those types. Of course, separate indexing of 655 fields still requires that decisions be made about form/genre headings in existing records coded in 650 fields. Can these be recoded, either automatically or manually? What are appropriate candidates for recoding? Managers must also consider what to do about headings, such as Science fiction in LCSH, which have been used both for subject and form/genre access. Automatic rather than manual recoding of these headings might not be feasible, depending on the size of the catalog and nature of the collection.

At Curry College, the Levin Library's system was profiled in 1995 with a separate form/genre index. Headings have been added to the index in three ways: deliberate provision of form/genre headings (primarily through video cataloging using $M I M$ ), recoding of 650 to 655 fields on an ad hoc basis (primarily via current cataloging), and acceptance of 655 fields on copy cataloging (primarily for works of fiction). We have plans to retrospectively convert and provide genre headings for particular literary genres, such as detective stories, for which classes are taught regularly at the college. As of May 1997, a section of the form/genre index contains these headings:

Medical films and video (Nonfiction)

Medical novels

Mock heroic literature

Musical fiction

Nature films and video (Nonfiction)

Nonsense verses

Pastoral fiction

Picaresque literature

Police films and programs

Political fiction

Political films and programs

Prison films and programs

Psychological fiction

Questions and answers

In the second approach, terms from all vocabularies are indexed in a single list and retrieved through a single search. Mandel notes (v), "the two major problems caused by this approach are: (1) obvious vocabulary clashes (e.g., the same term is postable in one vocabulary and non-postable in another), and (2) degradation of access to specialized collections." This is no less true where subject and form/genre vocabularies are mixed than it is with multiple-subject vocabularies. Two primary techniques for minimizing the difficulties with this approach are qualification of terms and editing of headings. Automated systems that allow qualification of terms, based on coded information in authority records, make it possible to clarify the scope of identical or similar headings used in the same index. For example, the unqualified heading Soap operas might be juxtaposed in a subject index with Soap operas (Video/Film). Qualifiers might also be manually added to headings from alternative lists, though this is more labor-intensive and might have to be undone after a system migration or upgrade.

It is also possible to create a policy mandating that specific headings from alternative lists not be used. This also implies an ongoing investment in policy maintenance and review and could result in a loss of headings that, again, would be useful with an improved system. Despite 
the drawbacks of the mixed-vocabulary approach, for many libraries this will be the most feasible in the short term.

The third approach, integrated vocabularies, involves different means of relating vocabularies through mapping and the creation of syndetic structures, such as micro- and macrothesauri. This is an area in which a great deal of research has been done (see Chaplan 1995 and Olson and Strawn 1997 for two recent reports). The creation of maps, which would allow machine-assisted switching between related headings, implies a more sophisticated relationship between thesauri than either segregated files or mixed vocabularies. Though the initial editorial effort can be significant, and ongoing review is required, the results can be shared among libraries and systems and need not be redeveloped by every agency. Where subject and form/genre vocabularies are mapped, however, it is essential that systems be able to distinguish among the proper objects of redirected searches. As an example, a subject search for studies of Melodrama (LCSH) should not be directed to examples of Melodrama (MIM) on film or video.

\section{Areas for Further Research}

The rational, deliberate provision of access to genres and forms raises a number of questions requiring further investigation. The series of comparisons that have been made between $L C S H$ and MIM should be replicated with other vocabularies. Do other form/genre thesauri overlap with $L C S H$ to a greater or lesser extent than does MIM? How true is this, not only for established headings, but for the elements in their authority records? How do these degrees of overlap affect the choice to establish separate indexes, provide automatic qualification of headings within a single index, or otherwise make explicit the meanings of similar headings? The same questions apply to overlaps among form/genre thesauri themselves, not just in comparison with $L C S H$ or other subject-access lists. There are a number of opportunities for vocabulary-mapping studies in these questions.
Research into the capabilities of automated systems - and communication with systems vendors regarding support for multiple thesauri-will be a continuing need for the foreseeable future. As of spring 1997, we are far from having universal support for either X55 MARC Authority fields or qualification of terms based on authority record coding. Enhanced front-end navigation to help the user determine whether subject or form/genre searching is desired is an area for investigation. In addition, algorithms will need to be developed so that systems can apply the mapped terms to appropriate bibliographic items, if mapping between subject and form/genre vocabularies is developed.

Researchers might also want to consider how library patrons will be instructed in the use of form/genre terms. While library instruction is generally not considered a technical services function, the introduction of form/genre indexes or inclusion of new vocabularies might be resisted due to the challenge of educating users. It was asserted above that library users probably have an intuitive understanding of the difference between "is" and "is about." Nevertheless, libraries have not provided explicit access to forms and genres in a consistent fashion (except to works of Western classical music) through $L C S H$. Introducing such explicit access will require additional instruction in many situations, and technical services librarians might be able to share insights with their colleagues in public services.

\section{CoNCLUSION}

The 27 pairs of headings studied, while identical in form between $\mathrm{LCSH}$ and $M I M$, diverge in application. That is, on the evidence of the authority records that support them, they cannot be regarded as duplicative. The quantitative comparison, of potential interest to the database manager responsible for managing an authority file, revealed that fewer than $10 \%$ of reference terms are shared between pairs of records. The qualitative comparison indicated the likely reason for this lack of duplication: the headings have different 
meanings, sometimes to a startling degree, and are intended to apply to different bibliographic objects.

The lack of actual identity expressed by erstwhile-identical headings should remind us that headings are names, as Julia Pettee $(1954,18)$ pointed out. My first name, and that of one of Michelangelo's statues, are identical only as character strings. The entities designated are very different. It is impossible that a sane person would regard them as the same thing, and yet the names are identical. The fact that different concepts may share the same name presents significant management challenges when multiple thesauri are used in one catalog. Nevertheless, if we consider a heading to be not only a character string, but also what that string designates, we might come to the conclusion that Gossip and Gossip, Drama and Drama, Game shows and Game shows have little in common. This is all the more true when one of the two designates what an item is, and the other, what it is about.

\section{WoRks CITED}

Association for Library Collections \& Technical Services/Library \& Information Technology Association/RASD Machine-Readable Bibliographic Information Committee. 1995. MARBI meeting minutes, ALA Annual Conference, Chicago, Illinois, June 24-26 (gopher://marvel.loc.gov/00//listarch/usmarc fan1995 min).

Bearman, David, and Richard Szary. 1987. Beyond authorized headings: Authorities as reference files in a multi-disciplinary setting. In Authority control symposium: $\mathrm{Pa}$ pers presented during the 14th annual ARLIS/NA conference, New York, N.Y., February 10, 1986, ed. Karen Muller, 6978. Tueson, Ariz: Art Libraries Society of North America.

Chaplan, Margaret A. 1995. Mapping Laborline Thesaurus terms to Library of Congress Subject Headings: Implications for vocabulary switching. Library quarterly 65, no. 1: 39-61.

International Federation of Library Associations and Institutions. Section on Classification and Indexing. Working Group on Guidelines for Subject Authority Files. 1993. Guidelines for subject authority and reference entries. Munich: K. G. Saur.
Johnson, Eric H., and Pauline A. Cochrane. 1995. A hypertextual interface for a searcher's thesaurus (http://csdl.tamu.edu/DL95/ papers/johncoch/johncoch.html).

Library of Congress. Cataloging Policy and Support Office. Collections Services. 1995. Library of Congress subject headings. 18th ed. Washington, D.C.: Cataloging Distribution Service, Library of Congress.

- Network Development and MARC Standards Office. 1991. USMARC concise formats. Washington, D.C.: Cataloging Distribution Service, LC.

Mandel, Carol A. 1987. Multiple thesauri in online library bibliographic systems. Washington, D.C.: Cataloging Distribution Service, LC.

Miller, David. 1992. Levels of compatibility between moving image materials: Genre terms and Library of Congress Subject Headings in a general library catalog. In Subject access to films and videos, ed. Sheila S.Intner and William E. Studiwell, 17-30. Lake Crystal, Minn.: Soldier Creek. 1995. Ambiguities in the use of certain Library of Congress subject headings for form and genre access to moving image materials. Cataloging \& classification quarterly 20, no. 1: 83-104.

Olson, Tony, and Gary Strawn. 1997. Mapping the LCSH and MeSH systems. Information technology \& libraries 16, no. 1: 5-19.

Olszewski, Lawrence J. 1994. Madonna, Brahms, and President Clinton: Reference use of the OCLC authority file. RQ 33: 395-403.

Pettee, Julia. 1954. A new principle in dealing with subject matter needed? Journal of cataloging and classification 10, no. 1: 17-19.

Richmond, Phyllis A. 1973. A thesaurus within a thesaurus: A study in ambiguity. In Toward a theory of librarianship: Essays in honor of Jesse Hauk Shera, ed. Conrad H. Rawski, 268-301. Metuchen, N.J.: Scarecrow.

Schmierer, Helen F. 1980. The relationship of authority control to the library catalog. Illinois libraries 62: 599-603.

Sinkankas, George M. 1972. A study in the syndetic structure of the Library of Congress list of subject headings. Master's thesis. Pittsburgh: Graduate School of Library and Information Science, University of Pittsburgh.

Stockton-San Joaquin County Public Library. 1995. Definition of X55 fields for genre/ form terms in the USMARC authority format. Proposal 95-11, presented to the USMARC Advisory Group for discussion by MARBI during the June 1995 American Library Association Conference 
(gopher://marvel.loc.gov/00/.listarch/ usmarc/95-11.doc).

Taylor, Arlene. 1997. ALA/ALCTS Committee documentation (http://www.pitt.edu/ agtaylor/ala/alac.htm).

Yee, Martha M., comp. 1988. Moving image materials: Genre terms. Washington, D.C.: Cataloging Distribution Service, LC.
Yee, Tom. 1997. Report to ALA ALCTS CCS Subject Analysis Committee (SAC) Subcommittee on Form Headings/Subdivisions Implementation. Presented at the subcommittee meeting, American Library Association Midwinter Conference, February 17 , Washington, D.C.

\section{APPENDIX A.}

Identical Headings in libraky of Congress Subject Headings and MOVING-IMAGE MATERIALS: GENRE TERMS

$\begin{array}{ll}\text { Advertising } & \text { Music videos } \\ \text { Anthologies } & \text { Musicals } \\ \text { Beauty contests } & \text { Newsreels } \\ \text { Computer animation } & \text { Parodies } \\ \text { Drama } & \text { Press conferences } \\ \text { Editorials } & \text { Propaganda } \\ \text { Erotica } & \text { Quiz shows } \\ \text { Fiction } & \text { Science fiction } \\ \text { Film noir } & \text { Soap operas } \\ \text { Game shows } & \text { Talent shows } \\ \text { Gossip } & \text { Talk shows } \\ \text { Interviews } & \text { Television } \\ \text { Melodrama } & \text { Vaudeville } \\ \text { Music } & \end{array}$

